\title{
An update on Peginterferon beta-1a Management in Multiple Sclerosis: results from an interdisciplinary Board of German and Austrian Neurologists and dermatologists
}

\author{
Annette Kolb-Mäurer ${ }^{1}$, Cord Sunderkötter ${ }^{2}$, Borries Kukowski ${ }^{3}$, Sven G. Meuth ${ }^{4^{*}}$ and on behalf of the members of
} an expert meeting

\begin{abstract}
Background: Interferon (IFN) beta drugs have been approved for the treatment of relapsing forms of multiple sclerosis (RMS) for more than 20 years and are considered to offer a favourable benefit-risk profile. In July 2014, subcutaneous (SC) peginterferon beta-1a $125 \mu \mathrm{g}$ dosed every 2 weeks, a pegylated form of interferon beta-1a, was approved by the EMA for the treatment of adult patients with RRMS and in August 2014 by the FDA for RMS. Peginterferon beta-1a shows a prolonged half-life and increased systemic drug exposure resulting in a reduced dosing frequency compared to other available interferon-based products in MS. In the Phase 3 ADVANCE trial peginterferon beta-1a demonstrated significant positive effects on clinical and MRI outcome measures versus placebo after one year. Furthermore, in the ATTAIN extension study, sustained efficacy with long-term treatment for nearly 6 years was shown.
\end{abstract}

Main text: In July 2016, an interdisciplinary panel of German and Austrian experts convened to discuss the management of side effects associated with peginterferon beta-1a and other interferon beta-based treatments in MS in daily practice. The panel was composed of experts from university hospitals and private clinics comprised of neurologists, dermatologists, and an MS nurse. In this paper we report recommendations regarding best practices for adverse event management, focussing on peginterferon beta-1a. Injection site reactions (ISRs) and influenzalike illness are the most common adverse effects of interferon beta therapies and can present a burden for MS patients leading to non-adherence and discontinuation of therapy. Peginterferon beta-1a shows improved pharmacological properties. In clinical trials, the adverse event (AE) profile of peginterferon beta-1a was similar to other interferon beta formulations. The most common AEs were mild to moderate ISRs, influenza-like illness, pyrexia, and headache. Current information on the underlying cause of skin reactions associated with SC interferon treatment, and the management strategies for these AEs are limited. In pivotal trials, ISRs were mainly characterized and classified by neurologists, while dermatologists were only rarely consulted.

Conclusions: This report addresses expert recommendations on the management of most relevant adverse effects related to peginterferon beta-1a and other interferon betas, based on literature and interdisciplinary experience.

Keywords: Multiple sclerosis, Peginterferon bet-1a, Interferon beta, Flu-like symptoms, Injection site reactions, Management

\footnotetext{
* Correspondence: sven.meuth@ukmuenster.de

${ }^{4}$ Klinik für Neurologie, Universitätsklinikum Münster,

Albert-Schweitzer-Campus 1, Gebäude A1, 48149 Münster, Germany

Full list of author information is available at the end of the article
}

(c) The Author(s). 2019 Open Access This article is distributed under the terms of the Creative Commons Attribution 4.0 International License (http://creativecommons.org/licenses/by/4.0/), which permits unrestricted use, distribution, and reproduction in any medium, provided you give appropriate credit to the original author(s) and the source, provide a link to the Creative Commons license, and indicate if changes were made. The Creative Commons Public Domain Dedication waiver (http://creativecommons.org/publicdomain/zero/1.0/) applies to the data made available in this article, unless otherwise stated. 


\section{Background}

Interferons are glycoproteins that have antiviral, antiproliferative, and immune regulatory functions. Since their initial description in 1957 [1], interferons have been increasingly used to treat a wide range of diseases worldwide. Interferon alpha was first approved in 1986 for the treatment of hairy cell leukemia and later in 1991 for hepatitis Non-A Non-B (now Hepatitis C). Non-pegylated interferon beta drugs were approved in the mid 1990s (EMA) for the treatment of relapsing MS (SC interferon beta-1b, 1995; intramuscular (IM) interferon beta-1a, 1997; SC interferon beta-1a, 1998). Since non-pegylated interferon betas are small proteins, they are rapidly cleared by the kidneys or degraded, and thus need to be given regularly, from once per week to every other day. Frequent parenteral application as well as AEs such as influenza-like illness and local injection site reactions (ISRs) might affect adherence to long-term therapy [2].

Pegylation is a well-established modification of therapeutic biologicals. It involves the covalent addition of a widely inert polyethylene glycol (PEG) moiety to therapeutic macromolecules, aiming at an improvement of their pharmacological properties. The PEG moiety increases the molecular mass of the drug, inhibits proteolysis, and reduces renal elimination, thus extending systemic drug exposure. Therefore, pegylated drugs usually enable significantly prolonged dosing intervals, with the potential added benefit of a more consistent exposure over time. Pegylation can be associated with reduced drug immunogenicity and side effects as antigenic epitopes are masked against recognition by immune cells and antibodies [3, 4].

Several pegylated drugs in different indications have been approved, including peginterferon alfa- $2 \mathrm{a}$ and peginterferon alfa-2b. Pegylation of the interferon alfa molecules (alpha-2a, alpha-2b) improved the pharmacological properties of these proteins compared to the non-pegylated original forms, thereby boosting therapeutic efficacy (doubling sustained virologic response [SVR, no detectable viral HCV RNA in the blood 6 months after the completion of antiviral therapy] with peginterferon alfa versus interferon alfa) and reducing treatment frequency without increasing toxicity [5-7].

With the aim of yielding a modified, optimized interferon beta-1a molecule for the treatment of MS that requires less frequent dosing while maintaining the safety profile of the unmodified protein, pegylated interferon beta-1a (peginterferon beta-1a) was developed and later approved in July 2014 by the EMA ( $125 \mu \mathrm{g}$ every 2 weeks) for the treatment of relapsing-remitting multiple sclerosis (RRMS). Phase 1 studies comparing the pharmacokinetics of peginterferon beta-1a with subcutaneous (SC) and intramuscular (IM) interferon beta-1a, respectively, demonstrated that peginterferon beta-1a provided a longer terminal half-life and greater systemic exposure compared with interferon beta-1a $[8,9]$.
ADVANCE was the pivotal 2-year, randomised, doubleblind, parallel group, placebo-controlled (in year 1) Phase 3 trial of peginterferon beta $125 \mu \mathrm{g}$ in patients with relapsing-remitting MS. Patients were randomized 1:1:1 to peginterferon beta-1a every 2 weeks, peginterferon beta- 1 a every 4 weeks, or placebo. At the end of year 1 , all patients who received placebo were re-randomized to receive peginterferon beta-1a either every 2 or 4 weeks. In year 1 , peginterferon beta-1a every 2 weeks (approved dose) demonstrated significantly higher clinical and MRI efficacy outcomes compared with placebo. Compared with year 1, annualized relapse rate (ARR) was lower in year 2. Patients starting peginterferon beta-1a every 2 weeks from year 1 displayed improved efficacy versus patients initially assigned to placebo, with reductions in ARR, 12-week disability progression, and 24-week disability progression (the latter was based on a post-hoc analysis and should be interpreted accordingly).

Over 2 years, greater reductions were observed with every 2 week versus every 4 week dosing for all endpoints [10]. In the ATTAIN extension study, relapse rates remained low up to nearly 6 years in the peginterferon beta-1a every 2week group [11]. Studies with direct comparison of efficacy in MS patients treated with peginterferon beta-1a versus non-pegylated interferon beta preparations have not been conducted. Thus, definite conclusions on their relative efficacy cannot be drawn from the available evidence.

The safety profile of peginterferon beta-1a in the pivotal ADVANCE trial was consistent with those of nonpegylated interferon beta preparations for relapsing forms of MS. Peginterferon beta-1a was generally well tolerated, with the majority of adverse events being of mild or moderate severity. The most common AEs reported after one year were erythema (62\% versus placebo $7 \%$ ), influenzalike illness ( $47 \%$ versus placebo $13 \%$ ), pyrexia ( $45 \%$ versus placebo $15 \%$ ), and headache (41\% versus placebo $33 \%$ ) [12]. The safety profile of peginterferon beta-1a over 5 years was similar to year 1 in the ADVANCE trial [20].

The Phase 1 COMPARE study was conducted to not only provide a direct comparison of drug exposure, but also to assess comparative safety and tolerability of a single peginterferon beta-1a $125 \mu \mathrm{g}$ dose versus 6 doses of SC interferon beta-1a (dosed at $44 \mu \mathrm{g}$, three times per week) over 2 weeks in healthy volunteers. The results demonstrated a significantly higher overall drug exposure $\left(\mathrm{AUC}_{0-336 \mathrm{~h}}\right.$ was $60 \% ; P<0.0001)$ with SC peginterferon beta-1a compared to SC interferon beta-1a. Peginterferon beta-1a dosing was associated with better tolerability, lower frequencies and incidence rates of ISRs, headache, myalgia and chills [9].

Although the results of the ADVANCE study show that ISRs and flu-like symptoms (FLS) associated with peginterferon beta-1a are mainly mild to moderate ( 95 and $90 \%$ respectively), and $<1 \%$ of patients discontinued treatment for this reason, these adverse events present a 
burden for MS patients and have a stronger impact on the patient's daily life when compared to the randomized controlled trial setting. Hence, in July 2016, a panel of experts from university hospitals and private clinics comprised of neurologists, dermatologists, and an MS nurse convened in order to discuss the management of side effects associated with SC peginterferon beta-1a and other interferon beta-based treatments in MS. This article presents the outcome of the expert assessment of safety and tolerability of interferon beta-based therapies in MS as well as recommendations on their management in daily clinical care with a focus on ISRs (Table 1).

\section{Main text}

\section{Management of side effects associated with IFN beta therapy in MS}

Recommendations by the authors and participating experts of the advisory board on mitigation strategies of adverse events (AEs) are discussed below in the context of published data and the respective Summary of Product Characteristics (SmPC). Population-based studies on the side-effect profile in sizeable populations treated in the routine treatment setting have not been published to date. Therefore, the content of this report is based on the

Table 1 Management of side effects

\begin{tabular}{l} 
Strategies for the management of skin reactions \\
- Patients should receive a detailed introduction on injection \\
echniques and precautions to avoid cutaneous adverse events. \\
- Warming the interferon solution to room temperature before \\
injection. \\
- Usage of an aseptic injection technique. \\
- Rotation of the subcutaneous injection site at each injection. \\
In the case of injection site erythema \\
- Cold black-tea compresses can be applied for anti-inflammatory \\
effects and cooling. \\
- To reduce pruritus and erythema, topic treatment with 5\% \\
polidocanol may be applied. \\
- Topical corticosteroids with appropriate therapeutic index in \\
case of more severe erythema and eczema, palpable, infiltrated \\
lesions, are e.g. prednicarbate (group II), mometasone (group III). \\
- In order to achieve an additional itch-relief effect, lotions, creams \\
and ointments can be stored in the refrigerator under hygienic \\
conditions. \\
Strategies for the management of FLS \\
- Patients should be informed about the possibility of the occurrence \\
and precautions to avoid or reduce FLS. \\
- Gradual titration of the (Peg)interferon beta dose at the initiation \\
of treatment according to the product information has been \\
shown to significantly ameliorate symptoms. \\
- Prophylactic and concurrent use of anti-inflammatory, analgesic \\
and/or antipyretic treatments such as acetaminophen, ibuprofen, \\
or naproxen may prevent or ameliorate FLSs. \\
- Optimal timing of injection should be determined individually. \\
\hline
\end{tabular}

available literature as of December $2017^{1}$ and personal opinion or communication.

\section{Skin reactions}

Injectable disease-modifying therapies (DMTs) can be associated with local skin reactions at the injection site and systemic cutaneous side effects. The pattern and incidence of ISRs appear to be dependent on the type of interferon (e.g. peginterferon beta-1a, interferon beta $1 \mathrm{a}$, interferon beta $1 \mathrm{~b}$ ) and route of administration (SC versus IM injection). In general, injection site reactions may present as erythema, bruises, swelling, induration, pain, pruritus, eczema-like reactions, infection, abscess, lipoatrophy or necrosis (Table 2, Fig. 1).

Low grade cutaneous reactions are observed in up to $90 \%$ of patients treated with subcutaneously administered interferon beta preparations (compared to $20 \%$ of patients using IM interferon beta-1a) [13, 14]. More severe skin reactions including cutaneous infections, deep ulcerations or necrosis are observed at low frequencies (1-5\%) [14, 15]. Generally, IM injections cause less skin reactions than SC injections, but cases with necrosis have also been reported for interferon beta-1a IM [14, 21].

In studies aiming at the identification of risk factors predisposing for skin reactions to injected interferon beta preperations, no correlations with preexisting atopic dermatitis, body mass index, gender or application via an autoinjector device ere observed. Lipoatrophy was observed somewhat more frequently in females versus male patients $[15,16]$. In general, local ISRs are seen more frequently in skin areas with less subcutaneous fat [17].

In contrast to local cutaneous side effects as described above, systemic immune-mediated and inflammatory cutaneous adverse events are rare [15]. Interferons have not been shown to play a definite causal role in most reported cases, thus it is unclear whether they truly contribute to the development of immune-mediated cutaneous adverse events [15].

In the ADVANCE trial, erythema, pain, and pruritus were the most commonly observed ISRs associated with peginterferon beta-1a therapy [12]. Of the patients who experienced ISRs, 95\% reported them as mild or moderate in severity. The described onset of erythema under peginterferon beta-1a was often delayed following injection, typically by more than $24 \mathrm{~h}$ (ca. $1-4$ days) in about $90 \%$ of patients [18]. The reported duration of ISR, usually more than 3 days, was longer than most patient experienced with non-pegylated interferon beta drugs [18]. However, erythema associated with peginterferon beta-1a treatment has not been demonstrated to be disruptive to patients' daily activities [18]. One patient experienced an injection site necrosis with SC 
Table 2 Skin reactions reported under therapy with peginterferon beta-1a, interferon beta 1a and 1b, respectively

\begin{tabular}{|c|c|c|c|c|}
\hline $\begin{array}{l}\text { Frequency according to } \\
\text { SmPC of respective drug }\end{array}$ & $\begin{array}{l}\text { SC peginterferon } \\
\text { beta-1a [19] }\end{array}$ & IM interferon beta-1a [21] & SC interferon beta-1a [22] & $\begin{array}{l}\text { SC interferon } \\
\text { eta } 1 \mathrm{~b}[23]\end{array}$ \\
\hline Very common $\geq 1 / 10$ & $\begin{array}{l}\text { IS erythema, IS pain, } \\
\text { IS pruritus }\end{array}$ & & $\begin{array}{l}\text { IS inflammation, IS skin disorder } \\
\text { reaction }\end{array}$ & $\begin{array}{l}\text { IS reaction (different } \\
\text { kinds), sweating }\end{array}$ \\
\hline $\begin{array}{l}\text { Common } \geq 1 / 100 \\
<1 / 10\end{array}$ & $\begin{array}{l}\text { IS oedema, IS warmth, } \\
\text { IS haematoma, IS rash, } \\
\text { IS swelling, IS } \\
\text { discolouration, IS } \\
\text { inflammation }\end{array}$ & $\begin{array}{l}\text { Rash, increased sweating, } \\
\text { contusion, IS pain, IS } \\
\text { erythema, IS bruising }\end{array}$ & $\begin{array}{l}\text { Pruritus, rash, erythematous } \\
\text { rash, maculo-papular rash, } \\
\text { alopecia, IS pain }\end{array}$ & $\begin{array}{l}\text { Erythema, swelling, } \\
\text { inflammation, pain, } \\
\text { abscess, skin disorder, } \\
\text { rash, urticaria, pruritus, } \\
\text { alopecia, IS necrosis }\end{array}$ \\
\hline $\begin{array}{l}\text { Uncommon } \geq 1 / 1.000 \text {, } \\
<1 / 100\end{array}$ & $\begin{array}{l}\text { Urticaria, hypersensitivity } \\
\text { reaction }\end{array}$ & Alopecia, IS burning & $\begin{array}{l}\text { Urticaria, IS necrosis, IS swelling, } \\
\text { IS infections*, increased sweating }\end{array}$ & Skin discolouration \\
\hline $\begin{array}{l}\text { Rare } \geq 1 / 10.000 \\
<1 / 1.000\end{array}$ & IS necrosis & & $\begin{array}{l}\text { Quincke's oedema (angio-oedema), } \\
\text { erythema multiforme, erythema, } \\
\text { multiforme-like skin reactions, } \\
\text { Stevens Johnson syndrome, IS } \\
\text { cellulitis, anaphylactic reactions }\end{array}$ & \\
\hline Unknown & & $\begin{array}{l}\text { Angioneurotic oedema, pruritus, } \\
\text { rash vesicular, urticaria, IS reaction, } \\
\text { IS inflammation, IS cellulitis, IS } \\
\text { necrosis, IS bleeding, anaphylactic } \\
\text { reactions, hypersensitivity reaction } \\
\text { (angio-oedema, dyspnea, urticarial, } \\
\text { rash, pruritus) }\end{array}$ & & $\begin{array}{l}\text { Drug induced lupus } \\
\text { erythematodes }\end{array}$ \\
\hline
\end{tabular}

peginterferon beta-1a in the pivotal ADVANCE trial, which was resolved with standard therapy. Hypersensitivity reactions occurred in $16 \%$ of patients receiving peginterferon beta-1a (14\% of patients with placebo), and $<1 \%$ of peginterferon beta- 1 a recipients experienced a serious hypersensitivity event (e.g. angioedema, urticaria). These patients recovered promptly following anti-histamine and/or corticosteroid therapy [19].

In the population of the extension study ATTAIN, injection-site reactions were less frequent in year 3-6 of therapy $(43 \%)$ vs. year 1-2 (70\%). Specifically, erythema, pain and pruritus were clearly reduced in the extension period vs. the double-blind phase [20]. Thus, it appears that the prevalence of local reactions declines with prolonged use of peginterferon beta-1a.

\section{Mitigation of injection-site reactions}

The expert panel recommended that before starting therapy, patients should be informed about the safety and tolerability profile of the injectable MS therapy. Patient education about the possibility that SC drugs may cause ISRs is an especially effective strategy to diminish anxiety when it occurs, as confirmed by two DELPHI surveys [18, 24], particularly when the onset of ISRs is delayed after the application. Illustrations showing the potential range of occurring erythema can help to set expectations. As recommended within the SmPC of the respective drug, healthcare professionals should train patients in the proper technique for self-administering subcutaneous injections to minimize cutaneous adverse events. As a practical measure, the experts suggested that patients should avoid
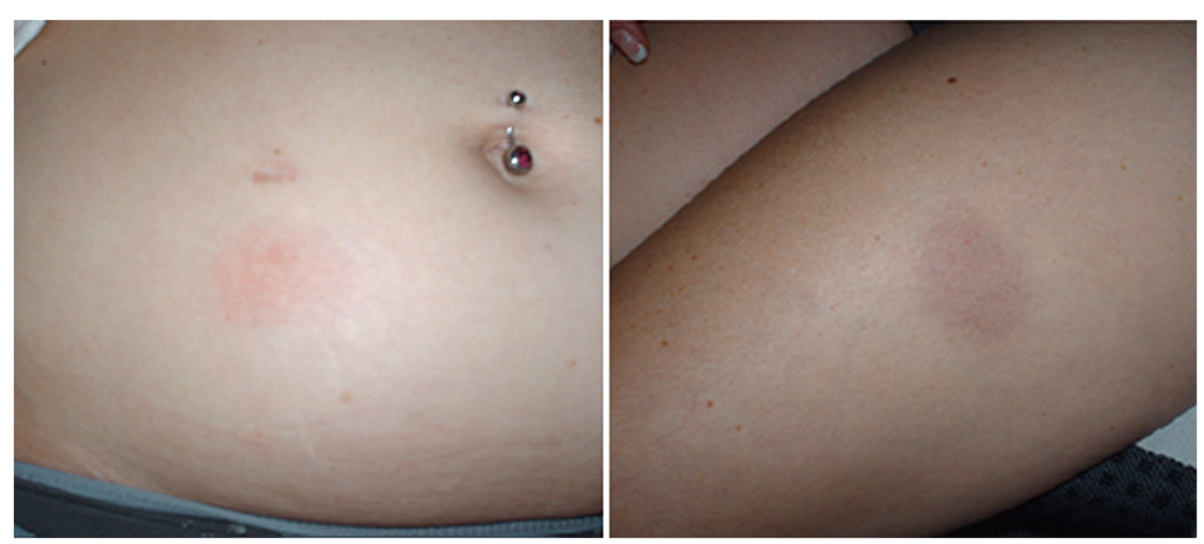

Fig. 1 Erythema observed in an adult patient injecting peginterferon beta-1a. (Image published with permission from expert. Patient consent was obtained for publication) 
injecting cold solution (directly out of the refrigerator) to reduce injection-related discomfort, and consequently the drug should be warmed to room temperature prior to injection [25]. The injection should not be applied in areas of the body where the skin is irritated, reddened, bruised, infected, tattooed or scarred in any way. The expert panel agreed with the label recommendations specifying that patients should also be advised to regularly rotate and not use the same injection site for consecutive injections [19].

The expert panel was of the opinion that pen devices and other autoinjectors have improved the convenience of administration and facilitate self-injection. They have reduced the burden of injectable MS-therapies and diminished problems associated with needle phobia and inadequate injection techniques. However, some patients still prefer to use the prefilled syringe instead of an injection device. A few of these patients report that they observed significantly less local cutaneous side effects when compared to autoinjector usage, independent of the interferon beta preparation [personal observation]. Patients who are apprehensive of SC injection might inject intradermally instead of subcutaneously due to a timid and halting injection procedure with an automatic administration device. In case of accidental intradermal injection (e.g. due to patient anxiety), the adverse skin reaction at the injection site may be increased. The prefilled syringe provides an alternative for patients who want to control the self-injection and are at risk of discontinuing therapy due to the autoinjector.

Patient support programs (PSP) with specialized nurses or skilled healthcare professionals have shown to enable continuous patient education and consistently confirmed treatment benefits [26]. The experts recommend to take advantage of special patient support programs or patient care by MS nurses. Accompanying patients in everyday practice may have strong positive psychological effects in some patients. Furthermore, MS patients are being informed on healthy skin practices and should be able to identify for signs and symptoms of ISRs or at least have the possibility to approach MS-nurses or specialized contact health care professionals within the PSP.

\section{Erythema, pruritus, swelling, and pain}

Injection-site pain, erythema, swelling, and pruritus may be reduced by applying warm compresses before injection and cold compresses after injection for up to $5 \mathrm{~min}$. The expert panel emphasized that the uses of ice packs for cooling of the affected areas is generally not advised, as it can lead to local frostbites. The tissue can be relaxed by warming or slightly massaging the area to improve medication absorption, prevent inflammation, and improve circulation so that the medication can be more easily dispersed from the area. A pilot study has been initiated to examine whether warm and cold compresses reduce injection site erythema due to peginterferon beta-1a [27]. Theoretically, both warm and cold modalities may improve interferon injection tolerance. Application of warm compresses before injection may increase local blood flow and rapid systemic absorption, while applying cold compresses after injection may reduce erythema, edema, and pain that often follows SC injections.

As recommended within the SmPC of the respective drug and reported previously, the site of administration should be disinfected (e.g. with an alcohol wipe) and dried before dosing [25].

Properly applied black-tea compresses can have an additional anti-inflammatory effect, and was endorsed by the dermatologists in the expert panel. Brewed unflavored black tea should steep for at least $20 \mathrm{~min}$, be chilled to the desired temperature (e.g. in the refrigerator under hygienic conditions), and placed on the affected skin with a single layer of linen cloth.

For local itch relief and redness, dermatologists of the expert panel recommend the drug polidocanol, which is a local anesthetic and antipruritic alkyl-polyglycolether that is used in the treatment of itching skin conditions, e.g. eczema [27, 28]. In the case of skin reactions that occur after administering SC interferons, the expert panel dermatologists recommend the use of $5 \%$ polidocanol as a formulation or as a component of a ready-to-use preparation. The application can be conducted as needed up to $5-10 \mathrm{x}$ per day.

Local antihistamine administration (e.g. dimetinden maleate), on the other hand, can cause dehydration of the skin and trigger allergies [29]; therefore, it was not recommended for mitigation of skin reactions at the injection site by the expert panel. When itching is very prominent, oral antihistamines were recommended instead by the expert panel; during the day, non-sedating antihistamines (e.g. desloratadine) and in the evening, optionally, sedating antihistamines (e.g. clemastine) were preferred.

Arnica preparation may cause contact dermatitis (allergies) which is usually attributed to the herbal compounds sesquiterpene lactones that may also have some anti-inflammatory properties [32]. Arnica is therefore less suitable and was not recommended by the dermatologists in the expert panel for management of local skin reactions after injections.

The application of vitamin $\mathrm{K}$ cream at the injection sites of non-pegylated interferon beta drugs has been show to reduce local reactions [31].

\section{Severe skin reactions, rash, and eczema}

In the case of severe skin reactions, rash and eczemalike reactions, higher-potency topical glucocorticoids of classes 2 to 4 (e.g. prednicarbate, mometasone or clobetasol) that have a good therapeutic index may be applied for 2-3 days post-injection (even on a large area, if necessary), as recommended by the dermatologists in the expert 
panel. In addition, as an occlusive treatment, the affected area may be enclosed overnight after treatment with the above glucocorticoids, e.g. with a plastic wrap or a waterproof bandage. As a result, the active substance penetrates into deeper skin layers. This technique may also be helpful in patients with recurrent skin reactions.

Topical hydrocortisone preparations are usually insufficient to manage inflammation and to mitigate injection site erythema.

\section{Skin infections or necrosis}

Severe skin reactions such as deep ulceration, infection or necrosis are rare adverse events and more likely seen under interferon beta- $1 \mathrm{~b}$ treatment as reported in the literature [14].

The pathogenesis of skin ulcerations and necrosis is still unclear. As discussed by the expert panel, unintended injection into deeper skin layers, e.g. into or around an artery can potentially lead to severe vasospasm (embolia cutis medicamentosa). It is also possible that the vessels that supply the arterial wall become punctured, triggering thrombotic occlusions. Patients usually report severe pain directly after the injection, followed by necrosis over the course of the following hours. Management of necrosis may require surgical treatment or antibiotics if infected.

One possible underlying cause for necrosis could be an immune complex vasculitis since an association between the occurrence of neutralizing antibodies to SC interferon beta and necrotizing skin lesion have been reported, [30], however, a genuine immune complex vasculitis would require palpable and retiform purpura in dependent body parts.

\section{Post-inflammatory hyperpigmentation}

A formation of hyperpigmentation is occasionally observed at sites of peginterferon beta-1a injection. Patients with this type of skin reaction, i.e. post-inflammatory hyperpigmentation, should avoid exposure of the affected skin to direct sunlight and UV irradiation. The hyperpigmentation may take several months or years to fade or may persist at sites where more severe local inflammatory reaction to the drug had occurred [personal observation].

\section{Flu-like symptoms}

FLS that include a variable combination of fever, myalgia, headache, asthenia, fatigue, and chills account for the most common adverse event in interferon-beta treated patients. The individual pattern and intensity of these symptoms also varies considerably. Incidence rates associated with non-pegylated interferon beta drugs have ranged from 40 to $61 \%$ in pivotal clinical trials [10, 12, 33-35]. The safety profile of peginterferon beta-1a observed in clinical trials and after approval was consistent with profiles observed after non-pegylated interferon beta treatments for relapsing MS [personal observation]. Next to ISRs, FLS are the most common side effects and include influenza like illness, pyrexia, headache, myalgia, chills, asthenia, and arthralgia. In the ADVANCE trial, influenza-like illness was experienced by $47 \%$ of patients receiving peginterferon beta-1a, and $13 \%$ of patients receiving placebo after 1 year $[10,12]$. Of the patients who reported FLS with peginterferon beta-1a dosed at $125 \mu \mathrm{g}$ every 2 weeks, $90 \%$ reported them as mild or moderate in severity. None were considered serious in nature. Less than $1 \%$ of patients who received peginterferon beta-1a during the ADVANCE study discontinued treatment due to FLS after 1 year [19].

Patients are more likely to experience FLS when initiating interferon beta therapy. The severity and incidence tend to decrease over time after continued therapy: In the population of the extension study ATTAIN, FLS were less frequent in year 3-6 (43\%) vs. year 1-2 (53\%). Fever in particular was observed in only $24 \%$ of the patients during the extension period vs. $50 \%$ in the double-blind phase [20].

FLS with non-pegylated IFN beta treatments typically occur relatively soon after the application, e.g. about two to six hours after injection, and usually improve within 24. h [17].

The median time to FLS onset after injection of peginterferon beta-1a in patients switching from interferon beta therapy to peginterferon beta-1a was $10 \mathrm{~h}$ (interquartile range, 7 to $16 \mathrm{~h}$ ) and the median duration was $17 \mathrm{~h}$ (interquartile range, 12 to $22 \mathrm{~h}$ ) [19]. With peginterferon beta1a injection every 2 weeks, the occurrence of FLS over the year is reduced due to the reduced frequency of injections versus non-pegylated interferon beta therapies.

As reported previously, the initiation phase of interferon treatment is the most critical period and can affect patients' views on the long-term acceptability of their therapy [17]. This shows the importance for mitigation strategies to reduce treatment-related adverse events such as FLS during the interferon initiation phase. In order to manage potential FLS, the experts also emphasized the benefit of special patient support programs or patient care by MS nurses. Patient education by MS nurses or a specialized health care professional within the PSP are also cited by the expert panel as essential for managing FLS.

\section{Titration and prophylactic co-medication}

The development of FLS is related to an interferon betainduced secretion of cytokines and mediators such as interleukin 6 (IL-6), interferon gamma, and prostaglandin levels. Detailed strategies to manage FLS in MS patients have been established including several nonpharmacological and pharmacological approaches [24].

There is no evidence-based guideline for the best time of the day to administer interferon beta because the 
pivotal efficacy studies conducted in the 1990s did not collect data regarding this issue. A consensus statement published in 1996 [36], however, recommends administering interferon beta in the evening before bedtime. The patient may sleep through the symptoms instead of experiencing them during active daytime periods. Alternatively, injecting in the morning can qualitatively improve interferon beta-related FLS and sleep [37]. However, since median FLS onset after peginterferon beta-1a treatment is $10 \mathrm{~h}$ after injection and is widely variable between patients (interquartile range between 7 and $16 \mathrm{~h}$ ), the experts agreed that the timing of the peginterferon beta-1a injection every 2 weeks should be considered individually [19].

Furthermore, the expert panel was in accordance with the label recommendations specifying that prophylactic and concurrent use of anti-inflammatory, analgesic and/ or antipyretic treatments such as acetaminophen, ibuprofen, or naproxen may prevent or ameliorate FLS sometimes experienced during interferon treatment [19].

The expert panel agreed that gradual titration of the interferon beta dose at the initiation of treatment according to the product information [19] has been shown to significantly ameliorate symptoms.

\section{Psychiatric disorders - depression}

The prevalence of psychiatric disorders is increased in MS [38]. The lifetime prevalence of major depressive disorder is higher compared to the general population (36-54\% versus 16.2\%), with an estimated doubling of suicide rates [39].

The association of depressed mood and diseasemodifying therapies, particularly interferon beta remains unclear $[41,43]$. While no significant increase in depression was found by several authors for IFN beta versus control groups [38-40] other authors observed higher rates in pateints receiving interferons [42-46].

In the ADVANCE study, the incidence of depression during the first year of study was similar in patients receiving peginterferon beta 1a compared to the placebo group. The overall incidence of depression or suicidal ideation was $8 \%$ for both peginterferon beta-1a and placebo [19]. Serious events of depression and suicidal ideation occurred infrequently $(<1 \%)$ in both groups.

An association of depression with interferon beta drugs remains a matter of debate, while depressive symptoms are generally observed more frequently in MS patients. The German DGN therapeutic guidelines recommend that affected patients should be observed more closely and early antidepressive therapy should be considered. The SmPCs of all interferon beta drugs include a warning regarding an increased frequency of depression in MS patients in general and in association with the use of interferon beta preparations. Thus, all interferon beta drugs and peginterferon beta-1a should be used with caution in MS patients with a history of depressive disorder. All interferon beta- based drugs are contraindicated in patients presenting with severe depression and/or suicidal ideation [1923]. The expert panel supports the recommendations of the gudelines.

\section{Laboratory abnormalities}

The use of interferons can be associated with laboratory abnormalities. The most commonly observed laboratory abnormalities that occur after the initiation of an interferon beta-therapy are lymphopenia, neutropenia, leukopenia, and raised liver aminotransferase values [17, 47].

\section{Hematologic adverse effects}

Hematologic adverse effects observed in patients receiving interferon beta preparation are generally mild, transient and self-limiting. The underlying mechanism is thought to be related to bone marrow $[48,49]$.

The healthy participants of a phase I study $(n=69)$, received a single dose of peginterferon beta-1a $(63 \mu \mathrm{g}$, $125 \mu \mathrm{g}, 188 \mu \mathrm{g}$; injected SC or IM) or IFN beta-1a (30 $\mu \mathrm{g}$ IM), respectively [8]. During follow-up, the cell numbers of lymphocyte subpopulations ( $\mathrm{T}$ cells, CD4+ and CD8+ cells, B cells, NK cells) decreased transiently on both tested drugs. Nadir levels were reached at $12 \mathrm{~h}$ post-injection with non-pegylated interferon beta-1a (reduction by 15 to $92 \%$ ) and between 12 and $24 \mathrm{~h}$ post-injection with peginterferon beta-1a (reduction by 9 to 92\%). The cell counts returned to baseline levels within $36 \mathrm{~h}$ after injection in the interferon beta-1a group. In the peginterferon beta-1a groups, baseline levels were reached at 7 days after injection, except for B cells that returned more slowly, with partial recovery observed by 28 days after application.

\section{Hepatic adverse effects}

Abnormal transaminase [alanine transaminase (ALT), aspartate transaminase (AST)] and bilirubin levels have been reported in patients receiving interferon betatherapy [49; FIs Betaferon; Plegridy]. Elevated serum hepatic enzyme levels, hepatitis, autoimmune hepatitis and hepatic failure has been reported in the post-marketing phase with interferon beta treatments. In some cases, these reactions have occurred in the presence of other co-medications (e.g. ibuprofen, naproxen, indomethacin) that have been associated with hepatic injury.

Hepatic monitoring is recommended and should be performed together with the other required laboratory monitoring (prior to initiation, in regular intervals following start of therapy, periodically thereafter in the absence of clinical symptoms). 


\section{Effects on thyroid function}

Autoimmunity and conditions associated with thyroid dysfunction such as hypothyroidism and hyperthyroidism have been observed with the use of interferon beta products. A review of the literature revealed an overall mean prevalence of incident thyroid dysfunction of $6.2 \%$ with hypothyroidism occurring more frequently (3.9\%) than hyperthyroidism (2.3\%) [50]. Thyroid disease has been reported especially in treated patients with preexisting autoimmunity. Although autoimmune reactions or immune system dysregulation provide the most likely explanation for the occurrence of thyroid disease with type I interferon therapy, a direct inhibitory effect on thyrocytes may be presumed in patients who developed hypothyroidism without autoimmunity [50].

Regular thyroid function tests are recommended in patients with a history of thyroid dysfunction or as clinically indicated.

The expert panel recommended to follow monitoring rules according to the product information and local guidelines [51, 52]: In addition to laboratory tests normally required for monitoring patients with MS, complete blood and differential blood cell counts, platelet counts, and blood chemistries including liver enzyme tests (e.g. AST, ALT), renal and thyroid function are recommended prior to initiation, at regular quarterly intervals within the first year following introduction of interferon therapy and then periodically thereafter in the absence of clinical symptoms, 1-2x per year (Table 3) [51, 52]. Patients with myelosuppression may require more intensive monitoring of complete blood cell counts, including differential and platelet counts.

\section{Conclusions}

In July 2014, peginterferon beta-1a, the first pegylated interferon beta-1a molecule, was approved by the EMA for the treatment of adult RRMS patients. Interferon beta therapies have been used for more than 20 years in the treatment of MS and have established themselves as effective and safe therapeutic options.
Peginterferon beta-1a allows for prolonged application intervals of 2 weeks with a safety and tolerability profile that appears largely similar to those of the nonpegylated interferon beta preparations. The prolonged dosing interval may support long-term adherence and persistence to the prescribed regimen.

The most common adverse events are mild to moderate erythema at the injection site and presence of FLS, although the latter occurs less frequently. The onset of FLS usually starts at $10 \mathrm{~h}$ after the injection, whereas FLS that occur after injection of non-pegylated interferon beta usually begin after about $6-8 \mathrm{~h}$. The management of interferon beta side effects has been established; for FLS, titration at the start of therapy, prophylactic and concurrent anti-inflammatory, analgesic and/or antipyretic co-medication as well as individual injection time is recommended. For ISRs, proper self-administration technique, rotation of the injection sites, warming of the injection solution to room temperature, cooling of the administration site after injection, and the use of topical preparations for potential ISRs are recommended.

The expert panel emphasized that educating patients (both treatment naïve and switchers) on the characteristics and management of potential adverse events, e.g. FLS and ISRs, before starting treatment is considered important for setting treatment expectations, promoting persistence/adherence, and improving treatment outcomes. During interferon treatment, the expert panel agreed that patients should be monitored as recommended by the SmPC and local guidelines.

Intensive patient care by the MS nurse or in special patient support programs has a strong psychological effect while accompanying patients in everyday practice.

Overall, there is more than 20 years of long-term safety and efficacy experience with interferons in patients with RRMS. Peginterferon beta-1a, with reduced frequency of injections, hence constitutes an attractive new option for the treatment of RRMS with an established benefit-risk ratio.

Table 3 Laboratory and MRI monitoring of interferon beta patients according to the German competence network multiple sclerosis (KKNMS) [52]

\begin{tabular}{|c|c|c|c|c|}
\hline & \multirow{2}{*}{$\begin{array}{l}\text { Prior to IFN } \\
\text { initiation }\end{array}$} & \multicolumn{3}{|c|}{ During IFN treatment } \\
\hline & & $\begin{array}{l}\text { After } 1 \text { month } \\
\text { of initiation }\end{array}$ & $\begin{array}{l}\text { Quarterly during first } \\
\text { year of treatment }\end{array}$ & $\begin{array}{l}1 \text { year of initiation: every } 6-12 \\
\text { months or as clinically indicated }\end{array}$ \\
\hline Complete, differential blood cell \& platelet counts & $x$ & $x$ & $x$ & $x$ \\
\hline Liver enzyme tests (ALT, AST, GGT, bilirubin) & $x$ & $x$ & $x$ & $x$ \\
\hline $\begin{array}{l}\text { Renal function (creatinine, estimated creatinine } \\
\text { clearance/GFR) }\end{array}$ & $x$ & $x$ & $x$ & $x$ \\
\hline Inflammation and Infections (urine status) & $x$ & & & \\
\hline TSH & & periodically & & \\
\hline Pregnancy test & $x$ & & & \\
\hline MRI & $x$ & annually & & \\
\hline
\end{tabular}




\section{Endnotes}

${ }^{11}$ Literature searches were performed in the PubMed database using "interferon(s)", "multiple sclerosis", "MS", "flu-like" and "FLS" as search terms.

\begin{abstract}
Abbreviations
AEs: Adverse events; ALT: Alanine aminotransaminase; AST: Aspartate aminotransferase; DGN: German Society of Neurology (Deutsche Gesellschaft für Neurologie); DMTs: Disease-modifying therapies; EMA: European Medicines Agency; FDA: US Food and Drug Administration; FLSs: Flu-like symptoms; GFR: Glomerular filtration rate; GGT: Gamma-glutamyl transferase; HCV: Hepatitis C virus; IFN: Interferon; IM: intramuscular; KKNMS: German competence network multiple sclerosis (Krankheitsbezogenes Kompetenznetz Multiple Sklerose); IS: Injection site; ISRs: Injection site reactions; MRI: Magnetic resonance imaging; MS: Multiple sclerosis; PSP: Patient support program; NK: Natural killer; RMS: Relapsing multiple sclerosis; RRMS: Relapsing remitting multiple sclerosis; SC: Subcutaneous; SmPC: Summary of product characteristics; SVR: Sustained virologic response, no detactable viral HCV RNA 6 months after end of therapy; $\mu$ g: Microgram
\end{abstract}

\section{Acknowledgements}

We gratefully acknowledge the discussions and contributions of all participants of the advisory board meeting: Annette Kolb-Maeurer, Cord Sunderkoetter, Borries Kukowski, Sven G. Meuth, Stefan Beissert, Gereon Nelles, Herbert Schreiber, Fritz Leutmezer, Til Menge, Christoph Lassek, Matthias Freidel, and Tanja Stirnweiß. Also, we acknowledge the editorial assistance of Christine Winterstein in the preparation of this manuscript.

\section{Authors' contributions}

AKM contributed to drafting the manuscript (focus: dermatological issues), revised the draft and approved the final manuscript. BK contributed to drafting the manuscript (focus: non-pegylated interferon beta), revised the draft and approved the final manuscript. CS contributed to drafting the manuscript (focus: pegylated interferon beta), revised the draft and approved the final manuscript. SM contributed to drafting the manuscript (focus: pegylated interferon beta), revised the draft and approved the final manuscript.

\section{Funding}

The advisory board meeting was supported by an unrestricted grant from Biogen $\mathrm{GmbH}$. Biogen provided funding for medical writing support in the development of this manuscript. Biogen was provided the opportunity to review and provide feedback on the manuscript.

\section{Availability of data and materials}

Not applicable.

\section{Ethics approval and consent to participate}

Not applicable.

\section{Consent for publication}

Not applicable.

\section{Competing interests}

AKM has received honoraria for lecturing and travel expenses for attending meetings from Biogen

BK has received honoraria for lecturing and travel expenses for attending meetings from Biogen, Genzyme, Novartis, Roche, Sanofi-Aventis and Teva. CS has received honoraria for lecturing and travel expenses for attending meetings from Biogen

SGM has received honoraria for lecturing, travel expenses for attending meetings and financial research support from Almirall, Bayer Health Care, Biogen, Diamed, Genzyme, Merck Serono, Novartis, Novo Nordisk, ONO Pharma, Roche, Sanofi-Aventis and Teva.

\section{Author details}

${ }^{1}$ Klinik und Poliklinik für Dermatologie, Venerologie und Allergologie, Universitätsklinikum Würzburg, Würzburg, Germany. ${ }^{2}$ Universitätsklinik und Poliklinik für Dermatologie und Venerologie, Ernst-Grube-Str. 40, 06120 Halle (Saale) und Abteilung für translationale Dermatoinfektiologie, Röntgenstraße 21, 48149 Muenster, Germany. ${ }^{3}$ Nervenärztliche Gemeinschaftspraxis,
Groner-Tor-Straße 3, 37073 Göttingen, Germany. ${ }^{4}$ Klinik für Neurologie, Universitätsklinikum Münster, Albert-Schweitzer-Campus 1, Gebäude A1, 48149 Münster, Germany.

Received: 21 July 2017 Accepted: 31 May 2019

Published online: 15 June 2019

\section{References}

1. Isaacs A, Lindenmann J. Virus interference. I. the interferon. Proc R Soc London Ser B, Biol Sci. 1957;147:258-67 http://www.ncbi.nlm.nih.gov/ pubmed/13465720. Accessed 2 Apr 2017

2. Devonshire V, Lapierre Y, Macdonell R, Ramo-Tello C, Patti F, Fontoura P, et al. The global adherence project (GAP): a multicenter observational study on adherence to disease-modifying therapies in patients with relapsingremitting multiple sclerosis. Eur J Neurol. 2011;18:69-77. https://doi.org/10. 1111/j.1468-1331.2010.03110.x.

3. Hartung H-P. Interferon $\beta$-1a for multiple sclerosis: old drug, new clothes. Lancet Neurol. 2014;13:638-9. https://doi.org/10.1016/S1474-4422(14)70100-0.

4. Baker DP, Pepinsky RB, Brickelmaier M, Gronke RS, Hu X, Olivier K, et al. PEGylated interferon beta-1a: meeting an unmet medical need in the treatment of relapsing multiple sclerosis. J Interf Cytokine Res. 2010;30:77785. https://doi.org/10.1089/jir.2010.0092

5. Zeuzem S, Welsch C, Herrmann E, Ph D. Pharmacokinetics of peginterferons. Semin Liver Dis. 2003;23(Suppl 1):23-8. https://doi.org/10.1055/s-2003-41631.

6. Zeuzem S, Feinman VR, Heathcote J, Ming-Yang L, Gane D, O'grady J, et al. Peginterferon alfa-2a in patients with chronic hepatitis C. N Engl J Med. 2000:343:1666-72

7. Lindsay KL, Trepo C, Heintges T, Shiffman ML, Gordon SC, Hoefs JC, et al. A randomized, double-blind trial comparing pegylated interferon alfa- $2 \mathrm{~b}$ to interferon alfa-2b as initial treatment for chronic hepatitis $C$. Hepatology. 2001:34:395-403.

8. Hu X, Miller L, Richman S, Hitchman S, Glick G, Liu S, et al. A novel PEGylated interferon Beta-1a for multiple sclerosis: safety, pharmacology, and biology. J Clin Pharmacol. 2012;52:798-808. https://doi.org/10.1177/0091270011407068.

9. Hu X, Shang S, Nestorov I, Hasan J, Seddighzadeh A, Dawson K, et al. COMPARE: pharmacokinetic profiles of subcutaneous peginterferon beta-1a and subcutaneous interferon beta-1a over 2 weeks in healthy subjects. $\mathrm{Br} J$ Clin Pharmacol. 2016;82:380-8. https://doi.org/10.1111/bcp.12968.

10. Kieseier BC, Arnold DL, Balcer LJ, Boyko AA, Pelletier J, Liu S, et al. Peginterferon beta-1a in multiple sclerosis: 2-year results from ADVANCE. Mult Scler. 2015:21:1025-35. https://doi.org/10.1177/1352458514557986.

11. Fiore $D$ et al. ADVANCE phase 3 extension study (ATTAIN): Peginterferon beta-1a 125 mcg every 2 weeks demonstrated sustained efficacy in RMS patients treated up to 5 years. AAN 2016; P4.010.

12. Calabresi PA, Kieseier BC, Arnold DL, Balcer LJ, Boyko A, Pelletier J, et al. Pegylated interferon beta-1a for relapsing-remitting multiple sclerosis (ADVANCE): a randomised, phase 3, double-blind study. Lancet Neurol. 2014:13:657-65. https://doi.org/10.1016/S1474-4422(14)70068-7.

13. Kappos L, Wiendl H, Selmaj K, Arnold DL, Havrdova E, Boyko A, et al. Daclizumab HYP versus interferon Beta-1a in relapsing multiple sclerosis. N Engl J Med. 2015;373:1418-28. https://doi.org/10.1056/NEJMoa1501481.

14. Balak DM, Hengstman GJ, Cakmak A, Thio HB. Cutaneous adverse events associated with disease-modifying treatment in multiple sclerosis: a systematic review. Mult Scler J. 2012;18:1705-17. https://doi.org/10.1177/1352458512438239.

15. Kolb-Mäurer A, Goebeler M, Mäurer M. Cutaneous adverse events associated with interferon- $\beta$ treatment of multiple sclerosis. Int J Mol Sci. 2015;16: 14951-60. https://doi.org/10.3390/ijms160714951.

16. Buttmann M, Goebeler M, Toksoy A, Schmid S, Graf W, Berberich-Siebelt F, et al. Subcutaneous interferon- $\beta$ injections in patients with multiple sclerosis initiate inflammatory skin reactions by local chemokine induction. J Neuroimmunol. 2005:168:175-82. https://doi.org/10.1016/j.jneuroim.2005.07.011.

17. Walther EU, Hohlfeld R. Multiple sclerosis: side effects of interferon beta therapy and their management. Neurology. 1999;53:1622. https://doi.org/10. 1212/WNL.53.8.1622.

18. Hendin B, Huang D, Wray S, Naismith RT, Rosenblatt S, Zambrano J, et al. Subcutaneous peginterferon $\beta$-1a injection-site reaction experience and mitigation: Delphi analysis of the ALLOW study. Neurodegener Dis Manag. 2017:7:39-47. https://doi.org/10.2217/nmt-2016-0032.

19. Plegridy ${ }^{\oplus}$, Summary of Product Characteristics. http://ec.europa.eu/health/ documents/community-register/2014/20140718129034/anx_129034_en.pdf. Accessed 3 Apr 2017. 
20. Cui $Y$ et al. ADVANCE phase 3 extension study (ATTAIN): Peginterferon beta-1a safety and tolerability remain favorable in RMS patients with up to 5 years of treatment. AAN 2016; P5.403.

21. Avonex ${ }^{\circledast}$, Summary of Product Characteristics. https://www.ema.europa.eu/ en/documents/product-information/avonex-epar-product-information_en. pdf Accessed 25 Apr 2019

22. Rebif ${ }^{\oplus}$, Summary of Product Characteristics. http://www.ema.europa.eu/ docs/en_GB/document_library/EPAR_-_Product_Information/human/ 000136/WC500048681.pdf. Accessed 3 Apr 2017

23. Betaferon ${ }^{\oplus}$, Summary of Product Characteristics. http://www.ema.europa.eu/ docs/en_GB/document_library/EPAR_-_Product_Information/human/ 000081/WC500053225.pdf. Accessed 3 Apr 2017.

24. Halper J, Centonze D, Newsome SD, Huang D, Robertson C, You X, et al. Management strategies for flu-like symptoms and injection-site reactions associated with Peginterferon Beta-1a. Int J MS Care. 2016;18:211-8. https:// doi.org/10.7224/1537-2073.2015-042.

25. Frohman EM, Brannon K, Alexander S, Sims D, Phillips JT, O'Leary S, et al. Disease modifying agent related skin reactions in multiple sclerosis: prevention, assessment, and management. Mult Scler. 2004;10:302-7. https://doi.org/10.1191/1352458504ms1002oa.

26. Katsarava Z, Ehlken B, Limmroth V, Taipale K, Patel SN, Niemczyk G, et al. Adherence and cost in multiple sclerosis patients treated with IM IFN beta1a: impact of the CARE patient management program. BMC Neurol. 2015; 15:170. https://doi.org/10.1186/s12883-015-0426-x.

27. A Pilot Study of Warm and Cold Compress to Reduce Injection Site Erythema Due to Peginterferon-beta-1a in MS - Full Text View - ClinicalTrials. gov. https://clinicaltrials.gov/ct2/show/NCT02490943?term=peginterferon+ beta-1a\&rank=11. Accessed 2 Apr 2017

28. Hawro T, Fluhr JW, Mengeaud V, Redoulès D, Church MK, Maurer M, et al. Polidocanol inhibits cowhage - but not histamine-induced itch in humans. Exp Dermatol. 2014;23:922-3. https://doi.org/10.1111/exd.12555.

29. Leroy A, Baeck M, Tennstedt D. Contact dermatitis and secondary systemic allergy to dimethindene maleate. Contact Dermatitis. 2011;64:170-1. https:// doi.org/10.1111/j.1600-0536.2010.01830.x.

30. Jocher A, Nist G, Weiss JM, Wetzel D, Merfort I, Jakob T, et al. Allergenic potential of Arnica-containing formulations in Arnica-allergic patients. Contact Dermatitis. 2009;61:304-6. https://doi.org/10.1111/j.1600-0536.2009.01638.x.

31. Lanzillo R, Moccia M, Carotenuto A, Vacchiano V, Satelliti B, Panetta V, Brescia Morra V. Vitamin $\mathrm{K}$ cream reduces reactions at the injection site in patients with relapsing-remitting multiple sclerosis treated with subcutaneous interferon beta - VIKING study. Mult Scler. 2015;21:1215-6.

32. Casoni F, Merelli E, Bedin R, Martella A, Cesinaro A, Bertolotto A. Necrotizing skin lesions and NABs development in a multiple sclerosis patient treated with IFNbeta 1b. Mult Scler. 2003;9:420-3. https://doi.org/10.1191/1352458503ms933sr.

33. Jacobs LD, Cookfair DL, Rudick RA, Herndon RM, Richert JR, Salazar AM, et al. Intramuscular interferon beta-1a for disease progression in relapsing multiple sclerosis. The multiple sclerosis collaborative research group (MSCRG). Ann Neurol. 1996;39:285-94. https://doi.org/10.1002/ana.410390304.

34. Interferon beta-1b in the treatment of multiple sclerosis: final outcome of the randomized controlled trial. The IFNB Multiple Sclerosis Study Group and The University of British Columbia MS/MRI Analysis Group. Neurology. 1995;45: 1277-85 http://www.ncbi.nlm.nih.gov/pubmed/7617182. Accessed 4 Sep 2016.

35. PRISMS Study Group and the University of British Columbia MS/MRI Analysis Group. PRISMS-4: long-term efficacy of interferon-beta-1a in relapsing MS. Neurology. 2001;56:1628-36 http://www.ncbi.n/m.nih.gov/pubmed/ 11425926. Accessed 14 Dec 2016.

36. Lublin FD, Whitaker JN, Eidelman BH, Miller AE, Arnason BG, Burks JS. Management of patients receiving interferon beta- $1 \mathrm{~b}$ for multiple sclerosis: report of a consensus conference. Neurology. 1996;46:12-8 http://www. ncbi.nlm.nih.gov/pubmed/8559358. Accessed 2 Apr 2017.

37. Nadjar $Y$, Coutelas E, Prouteau P, Panzer F, Paquet D, Saint-Val C, et al. Injection of interferon-beta in the morning decreases flu-like syndrome in many patients with multiple sclerosis. Clin Neurol Neurosurg. 2011;113:31622. https://doi.org/10.1016/j.clineuro.2010.12.013.

38. Goldman Consensus Group. The Goldman consensus statement on depression in multiple sclerosis. Mult Scler. 2005;11:328-37.

39. Minden SL, Feinstein A, Kalb RC, Miller D, Mohr DC, Patten SB, et al. Evidence-based guideline: assessment and management of psychiatric disorders in individuals with MS: report of the guideline development Subcommittee of the American Academy of neurology. Neurology. 2014;82: 174-81. https://doi.org/10.1212/WNL.0000000000000013.
40. Feinstein A. Multiple sclerosis, disease modifying treatments and depression: a critical methodological review. Mult Scler J. 2000;6:343-8. https://doi.org/ 10.1177/135245850000600509.

41. Schippling S, O'Connor P, Knappertz V, Pohl C, Bogumil T, Suarez G, et al. Incidence and course of depression in multiple sclerosis in the multinational BEYOND trial. J Neurol. 2016;263:1418-26.

42. Goeb JL, Even C, Nicolas G, Gohier B, Dubas F, Garré JB. Psychiatric side effects of interferon-beta in multiple sclerosis. Eur Psychiatry. 2006;21:186-93.

43. Goëb JL, Cailleau A, Lainé P, Etcharry-Bouyx F, Maugin D, Duverger P, et al. Acute delirium, delusion, and depression during IFN-beta-1a therapy for multiple sclerosis: a case report. Clin Neuropharmacol. 26:5-7 http://www. ncbi.nlm.nih.gov/pubmed/12567157. Accessed 2 Apr 2017.

44. Pandya $\mathrm{R}$, Patten $\mathrm{S}$. Depression in multiple sclerosis associated with interferon beta-1a (Rebif). Can J Psychiatr. 2002;47:686. https://doi.org/10. 1177/070674370204700720.

45. Patti F, Amato MP, Trojano M, Bastianello S, Tola MR, Picconi O, et al. Quality of life, depression and fatigue in mildly disabled patients with relapsing-remitting multiple sclerosis receiving subcutaneous interferon beta-1a: 3-year results from the COGIMUS (COGnitive impairment in MUltiple sclerosis) study. Mult Scler. 2011;17:991-1001. https://doi.org/10.1177/1352458511401943.

46. de Jong $H$, Kingwell $E$, Shirani $A$, et al. Evaluating the safety of b-interferons in MS. Neurology. 2017;88:2310-20.

47. Vial T, Descotes J. Clinical toxicity of the interferons. Drug Saf. 1994;10:11550 http://www.ncbi.nlm.nih.gov/pubmed/7516663. Accessed 19 Feb 2017.

48. Rieckmann P, O'Connor P, Francis GS, Wetherill G, Alteri E. Haematological effects of interferon-beta-1a (Rebif) therapy in multiple sclerosis. Drug Saf. 2004;27:745-56 http://www.ncbi.nlm.nih.gov/pubmed/15350158. Accessed 19 Feb 2017.

49. Tremlett $H$, Oger J. Hepatic injury, liver monitoring and the beta-interferons for multiple sclerosis. J Neurol. 2004;251:1297-303. https://doi.org/10.1007/ s00415-004-0619-5.

50. Monzani F, Caraccio N, Dardano A, Ferrannini E. Thyroid autoimmunity and dysfunction associated with type I interferon therapy. Clin Exp Med. 2004;3: 199-210. https://doi.org/10.1007/s10238-004-0026-3.

51. Klotz L, Berthele A, Brück W, Chan A, Flachenecker P, Gold R, et al. Monitoring von Blutparametern unter verlaufsmodifizierender MS-Therapie. Nervenarzt. 2016;87:645-59. https://doi.org/10.1007/s00115-016-0077-1.

52. Qualitätshandbuch Multiple Sklerose. http://www.kompetenznetzmultiplesklerose.de/wp-content/uploads/2016/12/KKNMS_Handbuch_ Gesamtausgabe_verknuepft_20160914_webfrei.pdf. Accessed 17 Dec 2016.

\section{Publisher's Note}

Springer Nature remains neutral with regard to jurisdictional claims in published maps and institutional affiliations.

\section{Ready to submit your research? Choose BMC and benefit from:}

- fast, convenient online submission

- thorough peer review by experienced researchers in your field

- rapid publication on acceptance

- support for research data, including large and complex data types

- gold Open Access which fosters wider collaboration and increased citations

- maximum visibility for your research: over $100 \mathrm{M}$ website views per year

At BMC, research is always in progress.

Learn more biomedcentral.com/submissions 